\title{
The effect of travel distance on health-related quality of life for patients with nephrolithiasis
}

Gopal L. Narang ${ }^{1}$; Laura E. Wiener ${ }^{2}$; Kristina L. Penniston ${ }^{3}$; Jodi A. Antonelli ${ }^{4}$; Timothy D. Averch $^{5}$; Sri Sivalingam ${ }^{6}$; Ben H. Chew ${ }^{7}$; Vincent G. Bird ${ }^{8}$; Vernon M. Pais Jr${ }^{9}$; Roger L. Sur ${ }^{10}$; Thomas Chi ${ }^{11}$; Necole M. Streeper ${ }^{12}$; Stephen Y. Nakada ${ }^{3}$; Gary G. Koch ${ }^{2}$; Davis P. Viprakasit ${ }^{1}$ ${ }^{1}$ University of North Carolina School of Medicine, Chapel Hill, NC, United States; ${ }^{2}$ Department of Biostatistics, University of North Carolina, Chapel Hill, NC, United States; ${ }^{3}$ University of Wisconsin School of Medicine and Public Health, Madison, WI, United States; ${ }^{4}$ University of Texas Southwestern Medical Center, Dallas, TX, United States; ${ }^{5}$ Palmetto Health USC Medical Group, Columbia, SC, United States; ${ }^{6}$ Glickman Urological \& Kidney Institute, Cleveland Clinic, Cleveland, $\mathrm{OH} ;{ }^{7}$ University of British Columbia, Vancouver, $\mathrm{BC}$, Canada; ${ }^{8}$ University of Florida College of Medicine, Gainesville, FL, United States; ${ }^{9}$ Geisel School of Medicine at Dartmouth, Hanover, NH, United States; ${ }^{10}$ University of California San Diego School of Medicine, San Diego, CA, United States; ${ }^{11}$ University of California San Francisco School of Medicine, San Francisco CA, United States; ${ }^{12}$ Penn State Health Milton S. Hershey Medical Center, Hershey PA, United States

Cite as: Can Urol Assoc J 2019 November 5; Epub ahead of print. http://dx.doi.org/10.5489/cuaj.6090

Published online November 5, 2019

$* * *$

\section{Abstract}

Introduction: Urolithiasis causes a significant impact on health-related quality of life (HRQOL). Patients with kidney stones have high levels of stress and anxiety. Symptom resolution often requires treatment. Travel distance is a barrier to care but little is known about its effects on HRQOL. We hypothesize that increased distance to treatment site is associated with decreased HRQOL.

Methods: Patients with a history of stones were enrolled at 11 tertiary centers as part of the QOL Stone Consortium of North America. HRQOL data were obtained using the Wisconsin Stone Quality of Life questionnaire (WISQOL). We calculated distance between patient and treatment site using national ZIP codes. We used linear models to evaluate the effect of distance on HRQOL, while also considering demographics data, stones/symptom status, and distance. Results: Of the 1676 enrolled patients, 52\% were male, $86 \%$ non-Latino White, and the mean age was 53 years. Mean distance to treatment site was $63.3 \mathrm{~km}$ (range: 0-3774), with 74\% reporting current stones and $45 \%$ current symptoms. WISQOL score and distance were negatively correlated for patients reporting current stones and symptoms $(p=0.0010)$. Linear 
modelling revealed decreased WISQOL scores for patients with symptoms as distance increased from treatment site $(\mathrm{p}=0.0001)$, with a 4.7 -point decrease for every $100 \mathrm{~km}$ traveled.

Conclusions: Stone disease imposes significant burden on patients' HRQOL due to a variety of factors. Patients with active stone symptoms report worse HRQOL with increased distance to their treatment site. Possible etiologies include travel burden, increased disease burden, decreased healthcare use, and delays in care.

\section{Introduction}

The impact of urolithiasis on health-related quality of life (HRQOL) is well known and significant. ${ }^{1,2}$ Patients suffering from urolithiasis have elevated levels of stress and higher rates of depression compared to national averages. ${ }^{3,4}$ Multiple studies evaluating HRQOL in stone disease have shown detriments in emotional, physical, and general health subscores. ${ }^{5,6}$ Urolithiasis not only causes personal suffering but affects work and family life, along with producing significant financial burden. ${ }^{7,8}$ The interplay between urolithiasis and HRQOL is complex, with a wide variety of environmental and patient-specific factors at play.

One such factor, distance to treatment site, has become an increasingly important consideration given trends toward regionalization in care. Regionalization has occurred in oncologic care, with high volume hospitals treating a larger proportion of prostate, bladder, and renal cancer than in the past. ${ }^{9,10}$ Complex stone care has similarly followed, with percutaneous nephrolithotomy being performed more frequently in teaching hospitals and high-volume centers. ${ }^{11}$ With regionalization, distance to treatment site increases for some and may represent a barrier to care. $^{12-15}$ The effects of distance on HRQOL, specifically in stone disease, have not been investigated.

There are limited studies evaluating the relationship between distance to care and HRQOL in urologic patients suffering from stone disease. The objective of our study was to investigate the relationship between distance to treatment site and HRQOL in patients with urolithiasis with data from a large multi-institutional cohort of stone patients.

\section{Methods}

\section{Study design, sites, and recruitment}

Our study is a cross-sectional analysis from a large multi-institutional study. Participants were recruited from 11 tertiary care centers across the United States and Canada between January 2016 and June 2017. The institutional review board at each site approved the study. Patients were eligible for enrollment if they were over the age of 18 , had a history of urolithiasis, and were English speaking. Initial enrollment occurred at outpatient urology or multidisciplinary clinic appointments. 


\section{Data collection}

All data were obtained at patient enrollment. The Wisconsin Stone Quality of Life questionnaire (WISQOL) was administered to and completed by participants at outpatient clinic appointments. The WISQOL questionnaire is a 28-item disease-specific HRQOL measure which evaluates four specific domains related to quality of life: social, emotional, stone-related symptoms impact, and vitality. Maximum total score is 140 points. The development and validation of the WISQOL questionnaire were discussed previously. ${ }^{16,17}$ Demographic information, including age, gender, BMI, race/ethnicity, duration of stone disease, number of previous stone events, and number of associated comorbidities, were obtained directly from the patient. Additionally, patients reported whether they were currently experiencing stones and/or stone-related symptoms as "Yes," "Not Sure," or "No." Patients also provided their zip code of residence.

\section{Statistical analysis}

Geodetic distance between patient and treatment site was calculated using national zip code data for US site and supplied for Canadian sites. In order to mitigate the influence of outliers, distance was censored at 500 kilometers $(\mathrm{km})$ - with distance greater than $500 \mathrm{~km}$ constituting the farthest $1 \%$. Given that current stone burden and symptoms were patient-reported and not radiographically confirmed, for all statistical analyses, patients reporting "Not Sure" to their stone or symptom status were considered to have positive status and recategorized as "Yes."

First, Spearman rank correlations $\left(r_{s}\right)$ were calculated between WISQOL score and distance - stratified by the presence of stones and/or symptoms. Next, linear models were fit to assess the effect of distance on WISQOL score while accounting for demographic and stonerelated factors. Factors considered for the model included: site, age, gender, BMI classification, race/ethnicity, duration of stone disease, previous stone events, associated comorbidities, presence of stones and/or symptoms, distance to treatment site, and the presence of stone/symptoms $\times$ distance interaction. Backward model selection was used to include only explanatory variables with $\mathrm{p}$-values deemed marginally predictive $(p<0.20)$. Spearman rank correlations were also calculated between distance and duration of stone disease, previous stone events, and age of onset - as these were viewed as possible surrogates for disease burden. For all analyses, statistical significance was concluded for $\mathrm{p}$-values less than the type I error $\alpha=0.05$. All statistical analyses were performed with SAS software Version 9.4 (Cary, North Carolina).

\section{Results}

\section{Patient characteristics}

Summaries of demographic data are presented in Table 1 for patients dichotomized to "Remote" or "Not Remote" and for the entire cohort. Remote was defined as having a distance in the third tertile, i.e., residing more than $45 \mathrm{~km}$ from treatment center. A total of 1676 participants were 
enrolled; however, distance data were unavailable for 11 participants therefore 1665 were included in the final analysis. This included 867 males and 798 females with a mean \pm standard deviation age of $52.8 \pm 14.3$ years. $73.6 \%$ of participants reported "Yes" or "Not Sure" to currently having stones and $44.9 \%$ reported "Yes" or "Not Sure" to currently experiencing symptoms attributed to stones.

Distance traveled to treatment site ranged from 0 to $3774.4 \mathrm{~km}$, with a mean distance of $55.4 \pm 81.91 \mathrm{~km}$ after censoring at $500 \mathrm{~km}$. Participants had a mean BMI of $30.3 \pm 7.5 \mathrm{~kg} / \mathrm{m}^{2}$, with $76.2 \%$ having a BMI of at least $25.0 \mathrm{~kg} / \mathrm{m}^{2}$. The majority of subjects, $85.5 \%$, identified themselves as non-Latino White, and 3.5\% identified as Black or African American. The mean age at onset of urolithiasis was $41.0 \pm 16.1$ years with a mean stone disease duration of $11.8 \pm$ 12.4 years. Subjects had a median of 3 prior stone events and 1 associated medical comorbidity. Mean WISQOL score and mean distance to treatment site are shown in Table 2 for each crossclassification of stone and symptom status.

\section{Spearman rank correlation}

Table 2 displays Spearman rank correlations for patients' quality of life and distance to treatment sites, stratified by stone and symptom status. For the entire sample there is a statistically significant negative correlation between WISQOL score and distance $\left(r_{s}=-0.110, p<\right.$ 0.0001). Furthermore, when considering the four mutually exclusive stone/symptom groups, $\mathrm{No} / \mathrm{No}, \mathrm{No} / \mathrm{Yes}, \mathrm{Yes} / \mathrm{No}$, and Yes/Yes, the negative correlation in the overall sample is driven by patients with both stones and symptoms (Yes/Yes) and symptoms but no stones (No/Yes). This can be seen through these groups having the most negative correlations $\left(r_{s}=-0.128\right.$ and -0.175 , respectively) and the Yes/Yes group with a p-value of 0.0010 . This trend is especially apparent when contrasted with the No/No and Yes/No groups ( $p=0.5809$ and 0.4607 , respectively). Thus, from the Spearman rank correlations, it can be seen that as distance increases, WISQOL score tends to decrease for those patients currently experiencing stonerelated symptoms but not for those with current stones and no symptoms or for those with neither stones nor symptoms.

Spearman rank correlations were also calculated between distance and three surrogate variables to evaluate the relationship between distance to treatment site and disease burden. There was a positive correlation between distance and duration of stone disease $\left(r_{s}=0.166\right.$, $p<0.0001)$ as well as prior stone events $\left(r_{s}=0.174, p<0.0001\right)$. There was a negative correlation between distance and age of disease onset $\left(r_{s}=-0.090,=0.0004\right)$. These findings suggest that patients living farther from their treatment site tend to have a longer duration of stone disease, more prior stone events, and be younger at disease onset - potentially signaling increased disease burden. 


\section{Linear modeling}

Based on the results from the Spearman correlations, a linear model was fit to assess the effects of demographic factors, stone disease factors, current stone status, and distance on WISQOL score in patients who reported experiencing symptoms. Through backward selection, duration of stone disease, gender, and the interaction of distance $\times$ current stone status (which assessed if the effect on WISQOL score of having stones changed as a function of distance) were excluded from the model with all p-values being greater than 0.20 . The estimated differences in WISQOL score for each factor, along with associated p-values, are shown in Table 3. Site, age, BMI classification, number of previous stone events, number of comorbidities, presence of current stones, and distance were all found to be statistically significant. Notably, the presence of current stones resulted in a very negative and significant effect on WISQOL score, with the presence of stones for those experiencing symptoms leading to an estimated 17 point drop in WISQOL score $(p<0.0001)$. Furthermore, the estimated effect of distance on WISQOL score for those subjects experiencing symptoms is $-0.047(p=0.0001)$. Thus, for every additional $100 \mathrm{~km}$ a patient with symptoms must travel, their total WISQOL score is expected to decrease by 4.7 points. Since the interaction between current stone status and distance was found to be not significant, having stones does not further compound the negative effect of distance on WISQOL score, i.e., for patients who are experiencing symptoms, the effect of having stones does not change as distance increases.

In our analysis, patients reporting "Not sure" in regards to their stone or symptom status were assumed to have positive status and recategorized as yes. In order to ensure that this did not unduly influence our results, we conducted sensitivity analyses by considering patients reporting "Not Sure" as "No" and by excluding them, seen in Supplemental Tables 1-4. Conclusions based on these sensitivity analyses, for both the Spearman correlations and the linear model, agree with the conclusions from the initial analysis considering patients reporting "Not Sure" as "Yes". This supports the robustness of our initial results and analysis.

\section{Discussion}

Stone disease produces significant symptoms and stress, resulting in higher rates of depression and anxiety. ${ }^{3,4}$ Symptoms from stones affect HRQOL at multiple points along the disease course. ${ }^{1,18,19}$ As a result, a push to better understand the HRQOL of patients with stone disease has been undertaken. This is clearly illustrated by the development of the WISQOL questionnaire, a stone-specific patient reported outcome measure that can evaluate changes in patient HRQOL from a variety of factors. ${ }^{20,21}$ One patient-specific factor that has not been well studied is distance to treatment site.

Ours is the first study evaluating the relationship between distance to treatment site and quality of life in the context of stone disease. We found that for those patients currently experiencing stone-related symptoms, there is a significant negative correlation between 
patients' WISQOL score and distance to treatment site. This relationship was not apparent in patients without symptoms, regardless of whether or not they reported having stones. Therefore, we infer that as patients experiencing stone-related symptoms have to travel farther for stone treatment, their HRQOL decreases. Even after taking demographic and stone disease factors into account, distance to treatment site had a significant effect on WISQOL score in patients experiencing symptoms - with an estimated decrease of 4.7 points for every $100 \mathrm{~km}$ traveled. Additionally, patients who currently report having stones in addition to symptoms scored an estimated 17 points lower on WISQOL, although this differential did not change with distance. To provide context, a 17 point decrease represents a $12 \%$ reduction in WISQOL score. For patients with stone-related symptoms, they experience an estimated $3 \%$ reduction in quality of life for every $100 \mathrm{~km}$ traveled.

Prior studies have shown negative relationships between distance to treatment site and factors related to stone care, such as follow up compliance after ureteroscopy, but no study has evaluated this relationship in the context of quality of life. ${ }^{22}$ Although a wide variety of etiologies are at play, increased burden of travel, increased disease burden, decreased health care utilization, and delays in timely care are likely the largest contributing factors.

The burden that increased travel distance places on quality of life cannot be understated. Modern health care costs put significant strain on patients financially. When these factors are compounded, increased travel distance can exacerbate the burden of healthcare costs - given the added cost of transportation and loss of patient and partner income while obtaining care. Furthermore, increased disease burden is likely playing a role. Our data suggest increased disease burden as patients travel farther for treatment - specifically, we noted longer duration of stone disease, more prior stone events, and a younger age at disease onset. Increased disease burden is likely a product and consequence of longer distance to treatment site. Ultimately, increased disease burden can impact patient's quality of life even before they begin to seek care.

Similarly, burden can arise from delays in obtaining timely care, which can result in underutilization. Patients living farther away from their treatment sites are known to utilize health care less frequently. ${ }^{23}$ Studies have demonstrated this point in rural populations and even found that patients may forego free medical care at distances as close as 20 miles, or $32 \mathrm{~km} .^{24}$ This propensity for decreased utilization may be due to lack of local care, socioeconomic factors, or a wide variety of other variables. Regardless, decreased utilization may be responsible for delays in obtaining care, which result in progression of disease, increased disease severity, persistent symptoms, and ultimately worsening quality of life. Overall, elevated cost, increased disease burden, delays in obtaining care and the propensity for decreased health care utilization are important sequalae of increased distance and produce significant effects on quality of life.

Some of the limitations of our study include its retrospective observational nature, which leaves it vulnerable to selection bias. Also, stone status was obtained by self-report, as opposed 
to radiographic data, thus potentially introducing response and/or measurement bias. All centers are tertiary care centers in North America, which predominantly face a greater burden of caring for patients with lower socioeconomic means and those without health insurance. ${ }^{25,26}$ This may affect HRQOL assessments as this sample may not be completely representative of the population of all patients with stone disease; although it can be argued that a similar patient population likely exists within the local area for direct comparison. We do recognize that our study population has a large proportion of Caucasian patients. This may represent an imbalance in our sample population or suggest a racial disparity in patients treated at centers of excellence, the latter of which is outside the scope of this study. Further, although we are able to point to differences in HRQOL based on stone and symptoms status and distance, we are yet to be able to evaluate their clinical significance. A minimally important difference for the WISQOL questionnaire has not been determined, although this is being investigated. Additionally, disease burden is assessed with the help of three surrogate variables. Though these provide a glimpse into the severity of disease, they may not be the best indicator. Currently, we are not able to speak specifically to stone burden, but future work will look to accurately assess stone burden to provide a more objective measure of disease burden. Further studies will evaluate which treatment modalities offer the best HRQOL. These centers are based across North America; therefore their applicability to the global landscape will remain to be seen depending on the particular model of health care in each region. Finally, since this is a cross-sectional analysis of HRQOL, changes in HRQOL over time are beyond the scope of this particular study.

There is no simple solution on how best to treat patients who must travel far for stone care. With a declining urologic workforce and aging population, disparities in the delivery of care are likely to increase in the future. ${ }^{27}$ The answer to this problem is likely to come from multiple avenues, including, but not limited to, leveraging new technologies and aggressive symptom control. Telemedicine provides a way to bridge the gap between patient and provider. Video visits are suitable alternatives to initial outpatient visits - saving patients from long travel distances and taking time off work. ${ }^{28}$ This could help providers stratify those patients who are farthest and have the highest symptom burden, thereby expediting further care.

Recent studies have brought attention to the effect stone symptoms have on HRQOL, independent of stone size or location and our study supports these findings. ${ }^{29}$ Aggressive symptom control may help to limit declines in HRQOL until treatment can be performed. Local providers may be hesitant to aggressively treat stone symptoms, especially in the climate of the opioid crisis and this is a valid concern. Educating them on the variety of multimodal techniques available may encourage more appropriate symptom control. One limitation is that we do not know whether the reason for travel for treatment is related to a specific physician's referral pattern or if a higher level of care is required due to patient or stone complexity. It is not possible 
to determine if centers closer to a patient with adequate capabilities to treat the stone are being bypassed.

Our study has shed light on the relationship between HRQOL and distance for individuals suffering from stone disease. This initial analysis is fundamental but raises important questions that require further investigation. Understanding the availability of local urologic care, and specifically endourologic care, may elucidate why patients travel for care. Ultimately, a better understanding of whether it is a global lack of urologic care or specialty urologic care will help tailor future interventions and potential distribution of health care. Further studies with additional data will be able to help determine the causes, in addition to distance, that impact a patient's HRQOL based upon their geographic location and distance to accessible health care.

\section{Conclusions}

Stone disease imposes significant burden on patients' HRQOL due to a variety of factors, spanning psychologic, physiologic, and economic components. A variety of patient-specific and environmental factors can influence this burden, and our study has found distance to be an important exacerbating factor. Patients with active stone symptoms report worse HRQOL with increased distance to their treatment site; possible etiologies include increased burden of travel, increased disease burden, decreased health care utilization, and delays in timely care. Continued work to better understand the relationship between distance to care and HRQOL among patients with active stone disease will help to develop future interventions. 


\section{References}

1. Penniston KL and Nakada SY: Treatment expectations and health-related quality of life in stone formers. Curr. Opin. Urol. 2016; 26: 50-5. Available at: http://www.ncbi.nlm.nih.gov/pubmed/26626885.

2. New F and Somani BK: A Complete World Literature Review of Quality of Life (QOL) in Patients with Kidney Stone Disease (KSD). Curr. Urol. Rep. 2016; 17: 1-6. Available at: http://dx.doi.org/10.1007/s11934-016-0647-6.

3. Angell J, Bryant M, Tu H, et al: Association of depression and urolithiasis. Urology 2012; 79: 518-525.

4. Miyaoka R, Ortiz-Alvarado O, Kriedberg C, et al: Correlation Between Stress and Kidney Stone Disease. J. Endourol. 2012; 26: 551-555. Available at: http://online.liebertpub.com/doi/abs/10.1089/end.2010.0536.

5. 5. Diniz DHMP, Blay SL and Schor N: Quality of life of patients with nephrolithiasis and recurrent painful renal colic. Nephron - Clin. Pract. 2007; 106: 91-97.

6. Penniston KL, Sninsky BC and Nakada SY: Preliminary Evidence of Decreased Disease-Specific Health-Related Quality of Life in Asymptomatic Stone Patients. J. Endourol. 2016; 30 Suppl 1: S42-5. Available at: http://online.liebertpub.com/doi/10.1089/end.2016.0074\%0Ahttp://www.ncbi.nlm.nih .gov/pubmed/26864746.

7. Saigal CS, Joyce G and Timilsina AR: Direct and indirect costs of nephrolithiasis in an employed population: Opportunity for disease management? Kidney Int. 2005; 68: $1808-1814$.

8. Hyams ES and Matlaga BR: Economic impact of urinary stones. Transl. Androl. Urol. 2014; 3: 278-83. Available at:

http://www.pubmedcentral.nih.gov/articlerender.fcgi?artid=4708578\&tool=pmcentre $z \&$ rendertype $=$ abstract.

9. Cooperberg MR, Modak S and Konety BR: Trends in Regionalization of Inpatient Care for Urological Malignancies, 1988 to 2002. J. Urol. 2007; 178: 2103-2108.

10. Anderson CB, Gennarelli R, Herr HW, et al: Regionalization of radical cystectomy in the United States. Urol. Oncol. Semin. Orig. Investig. 2017; 35: 528.e7-528.e13. Available at: http://linkinghub.elsevier.com/retrieve/pii/S1078143917301357.

11. Morris DS, Taub DA, Wei JT, et al: Regionalization of Percutaneous Nephrolithotomy: Evidence for the Increasing Burden of Care on Tertiary Centers. J. Urol. 2006; 176: 242-246.

12. Nemet GF and Bailey AJ: Distance and health care utilization among the rural elderly. Soc. Sci. Med. 2000; 50: 1197-1208.

13. Goodman DC, Fisher E, Slukel TA, et al: The distance to community medical care and the likelihood of hospitalization: Is closer always better? Am. J. Public Health 1997; 87: 1144-1150. Available at: http://www.ncbi.nlm.nih.gov/pubmed/9240104, accessed September 5, 2018.

14. Birklneyer JD, Siewers AE, Marth NJ, et al: Regionalization of High-Risk Surgery 
and Implications for Patient Travel Times. J. Am. Med. Assoc. 2003; 290: $2703-$ 2708. Available at:

http://jama.jamanetwork.com/article.aspx?doi=10.1001/jama.290.20.2703, accessed September 5, 2018.

15. McGuirk MA and Porell FW: Spatial patterns of hospital utilization: the impact of distance and time. Inquiry $1984 ; 21: 84-95$. Available at: https://www.jstor.org/stable/29771616, accessed September 5, 2018.

16. Penniston KL and Nakada SY: Development of an Instrument to Assess the Health Related Quality of Life of Kidney Stone Formers. J. Urol. 2013; 189: 921-930. Available at: http://linkinghub.elsevier.com/retrieve/pii/S0022534712049622.

17. Penniston KL, Antonelli JA, Viprakasit DP, et al: Validation and Reliability of the Wisconsin Stone Quality of Life Questionnaire. J. Urol. 2017; 197: 1280-1288. Available at: http://dx.doi.org/10.1016/j.juro.2016.11.097.

18. Donnally CJ, Gupta A, Bensalah K, et al: Longitudinal evaluation of the SF-36 quality of life questionnaire in patients with kidney stones. Urol. Res. 2011; 39: 141146. Available at: http://www.ncbi.nlm.nih.gov/pubmed/20924571, accessed July 25, 2018.

19. Bryant M, Angell J, Tu H, et al: Health related quality of life for stone formers. J. Urol. 2012; 188: 436-440. Available at: http://www.ncbi.nlm.nih.gov/pubmed/22704108, accessed July 25, 2018.

20. Streeper NM, Wertheim ML, Nakada SY, et al: Cystine Stone Formers Have Impaired Health-Related Quality of Life Compared with Noncystine Stone Formers: A Case-Referent Study Piloting the Wisconsin Stone Quality of Life Questionnaire Among Patients with Cystine Stones. J. Endourol. 2017; 31: S-48-S-53. Available at: http://www.ncbi.nlm.nih.gov/pubmed/27717296, accessed June 17, 2018.

21. Jiang H, Huang D, Yao S, et al: Improving Drainage After Percutaneous Nephrolithotomy Based on Health-Related Quality of Life: A Prospective Randomized Study. J. Endourol. 2017; 31: 1131-1138. Available at: http://www.ncbi.nlm.nih.gov/pubmed/28891320, accessed June 17, 2018.

22. Brooks NA, Paul CJ, Ghareeb GM, et al: Pushing Stones Uphill: Why Patients Are Lost to Follow-Up After Uncomplicated Ureteroscopy. J. Endourol. 2017.

23. Chan L, Hart LG and Goodman DC: Geographic Access to Health Care for Rural Medicare Beneficiaries. J. Rural Heal. 2006; 22: 140-146. Available at: http://doi.wiley.com/10.1111/j.1748-0361.2006.00022.x, accessed June 23, 2018.

24. Brustrom JE and Hunter DC: Going the distance: how far will women travel to undergo free mammography? Mil. Med. 2001; 166: 347-349. Available at: http://www.ncbi.nlm.nih.gov/pubmed/11315478, accessed June 23, 2018.

25. Calfee RP, Shah CM, Canham CD, et al: The influence of insurance status on access to and utilization of a tertiary hand surgery referral center. J. Bone Jt. Surg. - Ser. A 2012; 94: 2177-2184. Available at: http://www.ncbi.nlm.nih.gov/pubmed/23224388, accessed October 14, 2018.

26. Weiner BK, Black KP and Gish J: Access to spine care for the poor and near poor. Spine J. 2009; 9: 221-224. Available at: 
http://www.ncbi.nlm.nih.gov/pubmed/18468957, accessed October 14, 2018.

27. McKibben MJ, Kirby EW, Langston J, et al: Projecting the Urology Workforce Over the Next 20 Years. Urology 2016; 98: 21-26. Available at: http://www.ncbi.nlm.nih.gov/pubmed/27491965, accessed May 28, 2019.

28. Modi PK, Portney D, Hollenbeck BK, et al: Engaging telehealth to drive value-based urology. Curr. Opin. Urol. 2018; 28: 342-347.

29. Portis JL, Neises SM and Portis AJ: Pain is Independent of Stone Burden and Predicts Surgical Intervention in Patients with Ureteral Stones. J. Urol. 2018; 200: 597-603. Available at: http://www.jurology.com/doi/10.1016/j.juro.2018.04.075, accessed February 7, 2019. 


\section{Figures and Tables}

\begin{tabular}{|c|c|c|c|c|}
\hline Variable & & Not remote & Remote & Overall \\
\hline Distance $^{*}$ & & $1113,17.9 \pm 12.37$ & $552,154.7 \pm 277.65$ & $1665,63.3 \pm 172.55$ \\
\hline Distance (censored) ${ }^{*}$ & & $1113,17.9 \pm 12.37$ & $552,130.9 \pm 106.85$ & $1665,55.4 \pm 81.91$ \\
\hline Total WISQOL score* & & $1113,109.8 \pm 27.90$ & $552,102.5 \pm 31.08$ & $1665,107.4 \pm 29.19$ \\
\hline \multirow[t]{3}{*}{ Current stones } & Yes & $585(53.0)$ & $300(55.1)$ & $885(53.7)$ \\
\hline & Not sure & $218(19.8)$ & $110(20.2)$ & $328(19.9)$ \\
\hline & No & $300(27.2)$ & $134(24.6)$ & $434(26.4)$ \\
\hline \multirow[t]{3}{*}{ Current symptoms } & Yes & $371(33.7)$ & $240(44.3)$ & $611(37.2)$ \\
\hline & Not sure & $91(8.3)$ & $35(6.5)$ & $126(7.7)$ \\
\hline & No & $640(58.1)$ & $267(49.3)$ & $907(55.2)$ \\
\hline \multirow[t]{2}{*}{ Gender } & Female & $529(47.5)$ & $269(48.7)$ & $798(47.9)$ \\
\hline & Male & $584(52.5)$ & $283(51.3)$ & $867(52.1)$ \\
\hline Age (years) ${ }^{*}$ & & $1113,52.9 \pm 14.11$ & $552,52.6 \pm 14.59$ & $1665,52.8 \pm 14.27$ \\
\hline $\operatorname{BMI}\left(\mathrm{kg} / \mathrm{m}^{2}\right)^{*}$ & & $1098,29.7 \pm 6.93$ & $544,31.3 \pm 8.36$ & $1642,30.3 \pm 7.47$ \\
\hline \multirow{6}{*}{ BMI class } & Underweight & $14(1.3)$ & $10(1.8)$ & $24(1.5)$ \\
\hline & Normal & $262(23.9)$ & $105(19.3)$ & $367(22.4)$ \\
\hline & Overweight & $368(33.5)$ & $156(28.7)$ & $524(31.9)$ \\
\hline & Obese class I & $252(23.0)$ & $120(22.1)$ & $372(22.7)$ \\
\hline & Obese class II & $119(10.8)$ & $80(14.7)$ & $199(12.1)$ \\
\hline & Obese class III & $83(7.6)$ & $73(13.4)$ & $156(9.5)$ \\
\hline \multirow[t]{5}{*}{ Race - ethnicity } & Asian & $70(6.8)$ & $4(0.8)$ & $74(4.7)$ \\
\hline & $\begin{array}{l}\text { Black/African } \\
\text { American }\end{array}$ & $43(4.2)$ & $11(2.1)$ & $54(3.5)$ \\
\hline & White - Latino & $47(4.6)$ & $22(4.1)$ & $69(4.4)$ \\
\hline & White - non-Latino & $851(82.5)$ & $485(91.3)$ & $1336(85.5)$ \\
\hline & Other & $21(2.0)$ & $9(1.7)$ & $30(1.9)$ \\
\hline Age at onset (years) ${ }^{*}$ & & $1040,42.2 \pm 15.93$ & $518,38.7 \pm 16.16$ & $1558,41.0 \pm 16.08$ \\
\hline $\begin{array}{l}\text { Duration of stones } \\
\text { (years) }\end{array}$ & & $1039,10.7 \pm 12.04$ & $518,14.0 \pm 12.90$ & $1557,11.8 \pm 12.43$ \\
\hline Previous stone events ${ }^{\dagger}$ & & $968,2.3(4)$ & $483,4.0(8)$ & $1451,3.0(5)$ \\
\hline $\begin{array}{l}\text { Associated } \\
\text { comorbidities }^{\dagger}\end{array}$ & & $1113,1.0(3)$ & $552,2.0(2)$ & $1665,1.0(2)$ \\
\hline
\end{tabular}

"Remote" is defined universally at the overall $67^{\text {th }}$ percentile of $45 \mathrm{~km}$. Continuous variables (denoted *) are presented as $\mathrm{n}$, mean \pm standard deviation; count variables (denoted ${ }^{\dagger}$ ) are $\mathrm{n}$, median (interquartile range); and discrete variables are n (\%). BMI: body mass index; WISQOL: Wisconsin Stone Quality of Life questionnaire. 
Table 2. Spearman rank correlation between WISQOL score and distance to stone treatment centers by the presence of stones and/or symptoms

\begin{tabular}{|l|c|c|c|c|c|c|}
\hline Stones & Symptoms & $\mathbf{n}$ & Correlation & $\mathbf{p}$ & $\begin{array}{c}\text { Mean } \\
\text { WISQOL score }\end{array}$ & $\begin{array}{c}\text { Mean } \\
\text { distance (km) }\end{array}$ \\
\hline-- & -- & 1665 & -0.110 & $<0.0001$ & 107.4 & 55.4 \\
\hline-- & No & 907 & -0.008 & 0.8134 & 122.4 & 49.5 \\
\hline-- & Yes & 737 & -0.136 & 0.0002 & 89.3 & 61.5 \\
\hline No & -- & 434 & -0.011 & 0.8130 & 122.1 & 52.4 \\
\hline Yes & -- & 1213 & -0.129 & $<0.0001$ & 102.3 & 55.9 \\
\hline No & No & 362 & 0.029 & 0.5809 & 125.1 & 50.1 \\
\hline Yes & No & 544 & -0.032 & 0.4607 & 120.7 & 49.2 \\
\hline No & Yes & 72 & -0.175 & 0.1420 & 107.0 & 63.8 \\
\hline Yes & Yes & 665 & -0.128 & 0.0010 & 87.4 & 61.3 \\
\hline
\end{tabular}

"Not sure" is classified as "Yes" and distance is censored at $500 \mathrm{~km}$. WISQOL: Wisconsin Stone Quality of Life questionnaire. 


\begin{tabular}{|c|c|c|c|}
\hline Variable & & Estimate & $\mathbf{p}$ \\
\hline Intercept & & 98.560 & \\
\hline Site & & & $<0.0001$ \\
\hline Age (years) & & 0.362 & $<0.0001$ \\
\hline \multirow[t]{7}{*}{ BMI class } & & & 0.0249 \\
\hline & Underweight & -2.235 & \\
\hline & Normal & ref & \\
\hline & Overweight & 0.619 & \\
\hline & Obese class I & 1.174 & \\
\hline & Obese class II & -1.772 & \\
\hline & Obese class III & -11.026 & \\
\hline \multirow[t]{6}{*}{ Race - ethnicity } & & & 0.0571 \\
\hline & Asian & 8.051 & \\
\hline & Black/African American & -6.091 & \\
\hline & White - Latino & -5.760 & \\
\hline & White - non-Latino & ref & \\
\hline & Other & -16.035 & \\
\hline $\begin{array}{l}\text { Previous stone } \\
\text { Events }\end{array}$ & & -0.126 & 0.0322 \\
\hline Comorbidities & & -2.817 & 0.0002 \\
\hline Presence of stones & & -17.327 & $<0.0001$ \\
\hline Distance $(\mathrm{km})$ & & -0.047 & 0.0001 \\
\hline
\end{tabular}

Note: Distance has been censored at $500 \mathrm{~km}$. BMI: body mass index; WISQOL: Wisconsin Stone Quality of Life questionnaire. 


\section{Supplementary Tables}

\begin{tabular}{|l|c|c|c|c|c|c|}
\hline \multicolumn{8}{|l|}{$\begin{array}{l}\text { Supplementary Table 1. Spearman correlation of total QoL and distance (km) by } \\
\text { presence of stones and symptoms - Not sure" classified as "No }\end{array}$} \\
\hline Stones & Symptoms & n & Correlation & p & $\begin{array}{c}\text { Mean WISQOL } \\
\text { score }\end{array}$ & $\begin{array}{c}\text { Mean } \\
\text { distance }\end{array}$ \\
\hline-- & -- & 1665 & -0.110 & $<0.0001$ & 107.4 & 55.4 \\
\hline-- & No & 1033 & -0.011 & 0.7241 & 121.1 & 49.2 \\
\hline-- & Yes & 611 & -0.123 & 0.0023 & 84.8 & 64.4 \\
\hline No & -- & 762 & -0.037 & 0.3108 & 116.7 & 54.3 \\
\hline Yes & -- & 885 & -0.140 & $<0.0001$ & 99.6 & 55.5 \\
\hline No & No & 624 & 0.016 & 0.6834 & 122.3 & 49.4 \\
\hline Yes & No & 408 & -0.047 & 0.3400 & 119.2 & 49.0 \\
\hline No & Yes & 137 & -0.107 & 0.2112 & 92.0 & 75.5 \\
\hline Yes & Yes & 474 & -0.124 & 0.0068 & 82.7 & 61.3 \\
\hline
\end{tabular}

"Not sure" is classified as "No" and distance is censored at $500 \mathrm{~km}$. QoL: quality of life; WISQOL: Wisconsin Stone Quality of Life questionnaire.

\begin{tabular}{|c|c|c|c|c|c|c|}
\hline \multicolumn{7}{|c|}{$\begin{array}{l}\text { Supplementary Table 2. Spearman correlation of total QoL and distance }(\mathrm{km}) \text { by } \\
\text { presence of stones and symptoms - "Not sure" excluded }\end{array}$} \\
\hline Stones & Symptoms & $\mathbf{n}$ & Correlation & $\mathbf{p}$ & $\begin{array}{c}\text { Mean WISQOL } \\
\text { score }\end{array}$ & $\begin{array}{c}\text { Mean } \\
\text { Distance }\end{array}$ \\
\hline -- & -- & 1237 & -0.121 & $<0.0001$ & 106.8 & 54.6 \\
\hline -- & No & 717 & -0.005 & 0.8992 & 123.1 & 49.3 \\
\hline- & Yes & 520 & -0.133 & 0.0024 & 84.3 & 61.9 \\
\hline No & -- & 408 & 0.002 & 0.9716 & 122.3 & 52.2 \\
\hline Yes & -- & 829 & -0.146 & $<0.0001$ & 99.1 & 55.8 \\
\hline No & No & 362 & 0.029 & 0.5809 & 125.1 & 50.1 \\
\hline Yes & No & 355 & -0.035 & 0.5135 & 121.0 & 48.4 \\
\hline No & Yes & 46 & -0.165 & 0.2734 & 100.8 & 68.9 \\
\hline Yes & Yes & 474 & -0.124 & 0.0068 & 82.7 & 61.3 \\
\hline
\end{tabular}

"Not sure" is excluded and distance is censored at $500 \mathrm{~km}$. QoL: quality of life; WISQOL: Wisconsin Stone Quality of Life questionnaire. 


\begin{tabular}{|c|c|c|c|}
\hline $\begin{array}{l}\text { Supplementary Table } \\
\text { subjects currently ex } \\
\text { information, stone di } \\
\text { "Not sure" classified }\end{array}$ & $\begin{array}{l}\text { imated changes in } \\
\text { ing symptoms base } \\
\text { ctors, and distance } \\
\text {, }\end{array}$ & $\begin{array}{l}\text { OL score } \\
\text { demograp }\end{array}$ & \\
\hline Variable & & Estimate & $\mathbf{p}$ \\
\hline Intercept & & 92.479 & \\
\hline Site & & & 0.0016 \\
\hline Age (years) & & 0.260 & 0.0075 \\
\hline Gender & & & 0.1202 \\
\hline & Female & -3.714 & \\
\hline & Male & ref & \\
\hline BMI class & & & 0.0186 \\
\hline & Underweight & -2.161 & \\
\hline & Normal & ref & \\
\hline & Overweight & 1.229 & \\
\hline & Obese class I & 2.979 & \\
\hline & Obese class II & -4.355 & \\
\hline & Obese class III & -10.864 & \\
\hline Race - ethnicity & & & 0.0635 \\
\hline & Asian & 6.210 & \\
\hline & $\begin{array}{l}\text { Black/African } \\
\text { American }\end{array}$ & -4.609 & \\
\hline & White - Latin & -8.391 & \\
\hline & White - non-Latin & ref & \\
\hline & Other & -19.343 & \\
\hline Previous stone events & & -0.099 & 0.1107 \\
\hline Comorbidities & & -2.682 & 0.0012 \\
\hline Presence of stones & & -11.192 & 0.0001 \\
\hline Distance $(\mathrm{km})$ & & -0.043 & 0.0009 \\
\hline
\end{tabular}

Distance has been censored at $500 \mathrm{~km}$. BMI: body mass index; WISQOL: Wisconsin Stone Quality of Life questionnaire. 


\begin{tabular}{|l|l|c|c|}
\hline \multicolumn{4}{|l|}{ Table 4. Estimated changes in WISQOL score for subjects currently } \\
experiencing symptoms based on demographic information, stone \\
disease factors, and distance - "Not sure" excluded \\
\hline Variable & & 92.959 & Estimate \\
\hline Intercept & & & 0.0005 \\
\hline Site & & 0.296 & 0.0013 \\
\hline Age (years) & & & 0.0257 \\
\hline BMI class & & 7.187 & \\
\hline & Underweight & ref & \\
\hline & Normal & 0.963 & \\
\hline & Overweight & 3.757 & \\
\hline & Obese class I & -3.282 & \\
\hline & Obese class II & -10.012 & \\
\hline & Obese class III & -2.795 & 0.0003 \\
\hline Comorbidities & & -17.674 & $<0.0001$ \\
\hline Presence of stones & & -0.046 & 0.0011 \\
\hline Distance (km) & & & \\
\hline
\end{tabular}

Distance has been censored at $500 \mathrm{~km}$. BMI: body mass index; WISQOL: Wisconsin Stone Quality of Life questionnaire. 